\title{
Schanuel's Lemma in P-Poor Modules
}

\author{
Iqbal Maulana \\ Universitas Singaperbangsa Karawang,hmiqbal1202@gmail.com
}

doi: https://doi.org/10.15642/mantik.2019.5.2.76-82

\begin{abstract}
Abstrak: Modul merupakan perumuman dari ruang vektor aljabar linier yaitu dengan memperumum lapangan skalarnya menjadi ring dengan elemen satuan. Dalam teori modul terdapat konsep modul proyektif, yaitu suatu modul atas ring $R$ yang proyektif relatif terhadap semua modul atas $R$ Selanjutnya, diperoleh fakta bahwa setiap modul atas $R$ adalah modul proyektif relatif terhadap sebarang modul semisederhana atas $R$. Jika $P$ adalah suatu modul atas $R$ yang proyektif relatif hanya terhadap semua modul semisederhana atas $R$ saja, maka $P$ disebut modul $p$-miskin. Dalam pembahasan modul proyektif terdapat suatu lemma yang berkaitan dengan keekuivalenan dua buah modul $K_{1}$ dan $K_{2}$ dengan syarat terdapat dua buah modul proyektif $P_{1}$ dan $P_{2}$ sedemikian hingga $K_{1} \oplus P_{2}$ isomorfik dengan $K_{2} \oplus P_{1}$. Lemma tersebut dikenal sebagai lemma Schanuel di modul proyektif. Karena modul $p$-poor merupakan kasus khusus dari modul proyektif, maka pada tulisan ini akan dibahas tentang lemma Schanuel di modul $p$-poor.
\end{abstract}

Kata kunci: modul proyektif, modul semisederhana, modul p-poor, lemma Schanuel

\begin{abstract}
Modules are a generalization of the vector spaces of linear algebra in which the "scalars" are allowed to be from a ring with identity, rather than a field. In module theory there is a concept about projective module, i.e. a module over ring $R$ in which it is projective module relative to all modules over ring $R$. Next, there is the fact that every module over ring $R$ is projective module relative to all semisimple modules over ring $R$. If $P$ is a module over ring $R$ which it's projective relative only to all semisimple modules over ring $R$, then $P$ is called $p$-poor module. In the discussion of the projective module, there is a lemma associated with the equivalence of two modules $K_{1}$ and $K_{2}$ provided that there are two projective modules $P_{1}$ and $P_{2}$ such that $K_{1} \oplus P_{2}$ is isomorphic to $K_{2} \oplus P_{1}$ . That lemma is known as Schanuel's lemma in projective modules. Because the $p$-poor module is a special case of the projective module, then in this paper will be discussed about Schanuel's lemma in $p$-poor modules.
\end{abstract}

Keywords: projective module, semisimple module, p-poor module, Schanuel's lemma 


\section{Introduction}

Let $M$ and $N$ are $R$-modules, i.e. modules over a ring $R$. In this paper, $\operatorname{Mod}-R$ denotes the set of all right $R$-modules and SSMod-R the set of all semisimple right $R$-modules. An $R$-module is called a semisimple module if that module is a direct sum of simple modules [5]. A non-zero $R$-module is called a simple module if that module has no non-trivial submodules. In other words, its submodule is only $\{0\}$ and himself. Following [3], for any $R$-module $M, \mathfrak{P r} r^{-1}(M)=\{N \in \operatorname{Mod}-R \mid M$ is $N$ - projective module $\}$ is called the projectivity domain of $M$. If $\mathfrak{P r} r^{-1}(M)=\operatorname{Mod}$ $R$, then $M$ is called a projective module. Next, Alahmadi et al. [1] which discuss poor-module become the initial idea of the emergence of $p$-poor module concept, which $p$-poor module is dual of poor-module. Furthermore, this $p$-poor module is a special case of the projective module because the projectivity domain of $p$-poor only consists of all semisimple modules over ring $R$ [2]. Regarding the existence of the $p$-poor module, it was found that each ring has a $p$-poor module. As for the formation of the $p$-poor module, it was found that an $R$-module, which is the result of the direct sum of all cyclic modules over $R$ is a $p$-poor module [2].

This paper is inspired by similar ideas and problems in [4][5], where there is a lemma introduced by Stephen Schanuel in 1958 and known as the Schanuel's lemma in projective modules. That lemma associated with the equivalence of two modules $K_{1}$ and $K_{2}$ provided that there are two projective modules $P_{1}$ and $P_{2}$ such that $K_{1} \oplus P_{2}$ is isomorphic to $K_{2} \oplus P_{1}$. The organization of this paper describes as follows: section 2 explains a basic theory about exact sequences of $R$-modules and semisimple module. The explanation about the Schanuel's lemma in projective modules and Schanuel's lemma in $p$-poor modules will be presented in section 3. In section 4 , we conclude the discussion.

\section{Basic Theory}

In this section, we define the external direct sum, the short exact sequence, the split exact sequence, and some properties of the semisimple module.

\subsection{External Direct Sum}

Before we define the external direct sum, will first be discussed about the direct product.

Definition 2.1. [3] The cartesian product $\times_{A} X_{\alpha}$ of the sets $\left\{X_{\alpha}\right\}_{\alpha \in A}$ be the set of all $A$-tuple $\left(x_{\alpha}\right)_{\alpha \in A}$ such that $x_{\alpha} \in X_{\alpha}$, for all $\alpha \in A$. If $A$ is finite, $A=\{1, \ldots, n\}$ then be obtained $\times_{A} X_{\alpha}=X_{1} \times \ldots \times X_{n}=\left\{\left(x_{1}, \ldots, x_{n}\right) \mid x_{i} \in X_{i}, i=1, \ldots, n\right\}$.

Definition 2.2. [3] Let $\left\{M_{\lambda}\right\}_{\lambda \in \Lambda}$ be the set of $R$-modules. Defined the operations in $\times_{\Lambda} M_{\lambda}$, for every $\left(x_{\lambda}\right)_{\lambda \in \Lambda},\left(y_{\lambda}\right)_{\lambda \in \Lambda} \in \times_{\Lambda} M_{\lambda}$ and $r \in R$ then $\left(x_{\lambda}\right)_{\lambda \in \Lambda}+\left(y_{\lambda}\right)_{\lambda \in \Lambda}=\left(x_{\lambda}+y_{\lambda}\right)_{\lambda \in \Lambda}$ and $r\left(x_{\lambda}\right)_{\lambda \in \Lambda}=\left(r x_{\lambda}\right)_{\lambda \in \Lambda}$.

Next, the cartesian product $\times_{\Lambda} M_{\lambda}$, together with the above operations is $R$ modules. Furthermore, the module $\times_{\Lambda} M_{\lambda}$ is said to be the direct product of $\left\{M_{\lambda}\right\}_{\lambda \in \Lambda}$ and be written $\prod_{\Lambda} M_{\lambda}$.

Definition 2.3. [3] Let $\left\{M_{\lambda}\right\}_{\lambda \in \Lambda}$ be the set of $R$-modules. The external direct sum of $\left\{M_{\lambda}\right\}_{\lambda \in \Lambda}$ is defined as $\oplus_{\Lambda} M_{\lambda}=\left\{m \in \prod_{\Lambda} M_{\lambda} \mid \pi_{\lambda}(m) \neq 0\right.$ for $\lambda \in$ $\Lambda$ is finite $\}$. 


\subsection{Exact Sequences}

The concept of exact sequences of $R$-modules and $R$-module homomorphisms and their relation to direct summands is a useful tool to have available in the study of modules. We start by defining exact sequences of $R$-modules.

Definition 2.4. [6] Let $R$ be a ring. A sequence of $R$-modules $M$ and $R$-module homomorphisms $f$

$$
\stackrel{f_{i-1}}{\longrightarrow} M_{i-1} \stackrel{f_{i}}{\rightarrow} M_{i} \stackrel{f_{i+1}}{\longrightarrow} M_{i+1} \stackrel{f_{i+2}}{\longrightarrow} \ldots
$$

is said to be exact at $M_{i}$ if $\operatorname{Im}\left(f_{i}\right)=\operatorname{Ker}\left(f_{i+1}\right)$. The sequence is said to be exact if it is exact at each $M_{i}$.

As particular cases of Definition 2.1. note that if $M, M_{1}$, and $M_{2}$ are $R$-modules

1. $0 \rightarrow M_{1} \stackrel{f}{\rightarrow} M$ is exact if and only if $f$ is injective,

2. $M \stackrel{g}{\rightarrow} M_{2} \rightarrow 0$ is exact if and only if $g$ is surjective, and

3. The sequence

$$
0 \rightarrow M_{1} \stackrel{f}{\rightarrow} M \stackrel{g}{\rightarrow} M_{2} \rightarrow 0
$$

is exact if and only if $f$ is injective, $g$ is surjective and $\operatorname{Im}(f)=\operatorname{Ker}(g)$.

Definition 2.5. [7] Given a sequence of $R$-modules

$$
0 \rightarrow M_{1} \stackrel{f}{\rightarrow} M \stackrel{g}{\rightarrow} M_{2} \rightarrow 0
$$

1. The sequence (3) is said to be a short exact sequence if it is exact.

2. The sequence (3) is said to be a split exact sequence (or just split) if it is exact and if $\operatorname{Im}(f)=\operatorname{Ker}(g)$ is a direct summand of $M$.

Next, in the following theorem will be given a characterization of split exact sequence.

Theorem 2.1. [7] If

$$
0 \rightarrow M_{1} \stackrel{f}{\rightarrow} M \stackrel{g}{\rightarrow} M_{2} \rightarrow 0
$$

is a short exact sequence of $R$-modules, then the following are equivalent:

1. There exists a homomorphism $\alpha: M \rightarrow M_{1}$ such that $\alpha \circ f=i d_{M_{1}}$.

2. There exists a homomorphism $\beta: M_{2} \rightarrow M$ such that $g \circ \beta=i d_{M_{2}}$.

3. The sequence (4) is split exact.

If these equivalent conditions hold then

$$
\begin{aligned}
M & \cong \operatorname{Im}(f) \oplus \operatorname{Ker}(\alpha) \\
& \cong \operatorname{Ker}(g) \oplus \operatorname{Im}(\beta) \\
& \cong M_{1} \oplus M_{2}
\end{aligned}
$$

\subsection{Semisimple Module}

Next theory is needed in the next discussion is a semisimple module and some of its properties. However, it will first be defined as a simple module. 
Definition 2.6. [3] A non-zero $R$-module $M$ is called a simple module if $M$ has no non-trivial submodules. In other words, the submodule of $M$ is only $\{0\}$ and $M$.

Definition 2.7. [6] An $R$-module $M$ is called a semisimple module if $M$ is a direct sum of simple modules.

A semisimple module has some characterization which will be given in the following proposition.

Proposition 2.2. [6] For an $R$-module $M$, the following properties are equivalent:

1. $M$ is a semisimple module.

2. Every submodule of $M$ is a direct summand.

3. Every exact sequence $0 \rightarrow K \rightarrow M \rightarrow L \rightarrow 0$ splits, for each $K$ and $L$ are $R$ modules.

\section{Main Results}

Based on the previous introduction, we have that $p$-poor module is a special case of the projective module because the projectivity domain of $p$-poor only consists of all semisimple modules over ring $R$. In other words, $R$-modules $P$ is $p$ poor if for every semisimple $R$-modules $S$ satisfies for each epimorphism $g: S \rightarrow$ $N$ and homomorphism $f: P \rightarrow N$ there exists a homomorphism $h: P \rightarrow S$ such that $g \circ h=f$ (i.e. the following diagram commute).

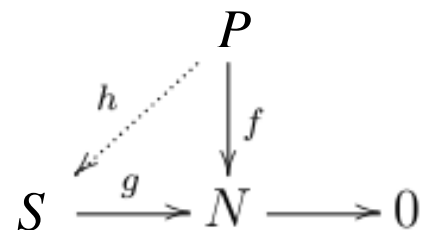

Therefore, before we explain Schanuel's lemma in $p$-poor modules, we will first discuss Schanuel's lemma in projective modules.

\subsection{Schanuel's Lemma in Projective Modules}

This lemma associated with the equivalence of two modules $M_{1}$ and $M_{2}$ provided that there are two projective modules $P_{1}$ and $P_{2}$ such that $M_{1} \oplus P_{2}$ is isomorphic to $M_{2} \oplus P_{1}$. Furthermore, it will be discussed in the following lemma.

Lemma 3.1. [4] Given the sequences of $R$-modules

$$
\begin{aligned}
& 0 \rightarrow M_{1} \stackrel{f_{1}}{\rightarrow} P_{1} \stackrel{g_{1}}{\rightarrow} M \rightarrow 0 \\
& 0 \rightarrow M_{2} \stackrel{f_{2}}{\rightarrow} P_{2} \stackrel{g_{2}}{\rightarrow} M \rightarrow 0
\end{aligned}
$$

If (5) and (6) are exact with $P_{1}$ and $P_{2}$ are projective, then $M_{1} \oplus P_{2}$ is isomorphic to $M_{2} \oplus P_{1}$.

Proof. From $R$-modules $P_{1}$ and $P_{2}$ can be formed a direct sum $P_{1} \oplus P_{2}$. Next, be formed $X=\left\{\left(p_{1}, p_{2}\right) \in P_{1} \oplus P_{2} \mid g_{1}\left(p_{1}\right)=g_{2}\left(p_{2}\right)\right\}$. Clearly, $X \subseteq P_{1} \oplus P_{2}$ and $X \neq \varnothing$ because $(0,0) \in X$. Then, for each $\left(x_{1}, x_{2}\right)$ and $\left(y_{1}, y_{2}\right)$ in $X$ and $r$ in $R$, we 
see that $g_{1}\left(x_{1}+y_{1}\right)=g_{1}\left(x_{1}\right)+g_{1}\left(y_{1}\right)=g_{2}\left(x_{2}\right)+g_{2}\left(y_{2}\right)=g_{2}\left(x_{2}+y_{2}\right)$ and $g_{1}\left(x_{1} r\right)=g_{1}\left(x_{1}\right) r=g_{2}\left(x_{2}\right) r=g_{2}\left(x_{2} r\right)$. So, we have $\left(x_{1}+y_{1}, x_{2}+y_{2}\right)$ and $\left(x_{1} r, x_{2} r\right)$ in $X$. In other words, $X$ is submodule of $P_{1} \oplus P_{2}$.

Next, we see that $g_{1}$ is epimorphism (surjective homomorphism) so that we have $M=g_{1}\left(P_{1}\right)$. Since $g_{2}$ is also epimorphism, then for each $g_{1}\left(P_{1}\right) \in M$ there exists $p_{2} \in P_{2}$ such that $g_{1}\left(p_{1}\right)=g_{2}\left(p_{2}\right)$. Defined homomorphism $\pi_{1}: X \rightarrow P_{1}$ with $\pi_{1}\left(p_{1}, p_{2}\right)=p_{1}$. Then, we have

$$
\begin{aligned}
\operatorname{Ker}\left(\pi_{1}\right) & =\left\{\left(p_{1}, p_{2}\right) \mid \pi_{1}\left(p_{1}, p_{2}\right)=0\right\} \\
& =\left\{\left(p_{1}, p_{2}\right) \mid p_{1}=0\right\} \\
& =\left\{\left(0, p_{2}\right) \mid g_{2}\left(p_{2}\right)=0\right\} \\
& \cong \operatorname{Ker}\left(g_{2}\right) \\
& =I^{\prime} m\left(f_{2}\right)
\end{aligned}
$$

Furthermore, based on the particular cases of Definition 2.1, because (6) are exact, then $f_{2}$ is monomorphism (injective homomorphism), and because $f_{2}$ is injective, then we have $\operatorname{Im}\left(f_{2}\right) \cong M_{2}$. As a result, we have $\operatorname{Ker}\left(\pi_{1}\right) \cong M_{2}$. Next, can be formed a short exact sequence

$$
0 \rightarrow M_{2} \rightarrow X \stackrel{\pi_{1}}{\rightarrow} P_{1} \rightarrow 0
$$

Since $P_{1}$ is a projective module, there exists a homomorphism $h: P_{1} \rightarrow X$ such that $\pi_{1} \circ h=i d_{P_{1}}$, then the sequence (7) is split exact, and we have $X \cong M_{2} \oplus P_{1}$. Furthermore in an analogous way, then can be formed a short exact sequence

$$
0 \rightarrow M_{1} \rightarrow X \stackrel{\pi_{2}}{\rightarrow} P_{2} \rightarrow 0
$$

and we have $X \cong M_{1} \oplus P_{2}$. Therefore, we have $M_{1} \oplus P_{2} \cong M_{2} \oplus P_{1}$.

\subsection{Schanuel's Lemma in P-Poor Modules}

Next, can be made Schanuel's lemma in $p$-poor modules, i.e. we replace sufficient conditions projective module in Lemma 3.1. with $p$-poor module which it is also a semisimple module, or we call that module as a semisimple $p$-poor. This is because the $p$-poor module is a special case of the projective module, where the projectivity domain of $p$-poor only consists of all semisimple modules. Therefore, need a certain condition is semisimple so that the concept of its projective module can be used in the $p$-poor module.

Lemma 3.2. Given the sequences of $R$-modules

$$
\begin{aligned}
& 0 \rightarrow M_{1} \stackrel{f_{1}}{\rightarrow} P_{1} \stackrel{g_{1}}{\rightarrow} M \rightarrow 0 \\
& 0 \rightarrow M_{2} \stackrel{f_{2}}{\rightarrow} P_{2} \stackrel{g_{2}}{\rightarrow} M \rightarrow 0
\end{aligned}
$$

If (9) and (10) are exact with $P_{1}$ and $P_{2}$ are semisimple $p$-poor modules, then $M_{1} \oplus$ $P_{2}$ is isomorphic to $M_{2} \oplus P_{1}$.

Proof. From semisimple $p$-poor modules $P_{1}$ and $P_{2}$, then we have $P_{1} \oplus P_{2}$ is also semisimple $p$-poor module. Next, be formed $W=\left\{\left(p_{1}, p_{2}\right) \in P_{1} \oplus\right.$ $\left.P_{2} \mid g_{1}\left(p_{1}\right)=g_{2}\left(p_{2}\right)\right\}$. Clearly, $W$ is a submodule of $P_{1} \oplus P_{2}$ because its proof is same with the proof of $X$ is a submodule of $P_{1} \oplus P_{2}$ in Lemma 3.1. Furthermore, according to [3] because every submodule of a semisimple module is semisimple, then we have $W$ is a semisimple module.

Next, we see that $g_{1}$ is epimorphism (surjective homomorphism) so that we have $M=g_{1}\left(P_{1}\right)$. Since $g_{2}$ is also epimorphism, then for each $g_{1}\left(P_{1}\right) \in M$ there exists 
$p_{2} \in P_{2}$ such that $g_{1}\left(p_{1}\right)=g_{2}\left(p_{2}\right)$. Defined homomorphism $\pi_{1}: W \rightarrow P_{1}$ with $\pi_{1}\left(p_{1}, p_{2}\right)=p_{1}$. Then, we have

$$
\begin{aligned}
\operatorname{Ker}\left(\pi_{1}\right) & =\left\{\left(p_{1}, p_{2}\right) \mid \pi_{1}\left(p_{1}, p_{2}\right)=0\right\} \\
& =\left\{\left(p_{1}, p_{2}\right) \mid p_{1}=0\right\} \\
& =\left\{\left(0, p_{2}\right) \mid g_{2}\left(p_{2}\right)=0\right\} \\
& \cong \operatorname{Ker}\left(g_{2}\right) \\
& =\operatorname{Im}\left(f_{2}\right)
\end{aligned}
$$

Furthermore, because $f_{2}$ is monomorphism (injective homomorphism), then we have $\operatorname{Im}\left(f_{2}\right) \cong M_{2}$. As a result, we have $\operatorname{Ker}\left(\pi_{1}\right) \cong M_{2}$. Next, can be formed a short exact sequence

$$
0 \rightarrow M_{2} \rightarrow W \stackrel{\pi_{1}}{\rightarrow} P_{1} \rightarrow 0
$$

Since $P_{1}$ is a $p$-poor module (i.e. projective module which its projectivity domain only consists of all semisimple modules), then for semisimple module $W$ there exists homomorphism $h: P_{1} \rightarrow W$ such that $\pi_{1} \circ h=i d_{P_{1}}$. In other words, the sequence (11) is split exact and we have $W \cong M_{2} \oplus P_{1}$. Furthermore in an analogous way, then can be formed a short exact sequence

$$
0 \rightarrow M_{1} \rightarrow W \stackrel{\pi_{2}}{\rightarrow} P_{2} \rightarrow 0
$$

and we have $W \cong M_{1} \oplus P_{2}$. Therefore, we have $M_{1} \oplus P_{2} \cong M_{2} \oplus P_{1}$.

\section{Conclusion}

Some properties which have sufficient conditions of the projective module can be modified by replacing the projective module into the $p$-poor module with certain additional conditions. The result of this research only discuss how to get Schanuel's lemma in $p$-poor modules, i.e. with modify Schanuel's lemma in projective modules. Its method is to replace sufficient conditions projective module on Schanuel's lemma in projective modules with a semisimple $p$-poor module. This is because the $p$-poor module is a special case of the projective module, where the projectivity domain of $p$-poor only consists of all semisimple modules. Actually, this lemma also as an introduction of an equivalence relation in the $p$-poor module, i.e. modules $M_{1}$ and $M_{2}$ are equivalent if there exist semisimple $p$-poor modules $P_{1}$ and $P_{2}$ such that $M_{1} \oplus P_{2}$ is isomorphic to $M_{2} \oplus P_{1}$. 


\section{References}

[1] A. N. Alahmadi, M. Alkan, and S. R. Lopez-Permouth, "Poor Modules: The Opposite of Injectivity," Glasgow Mathematical Journal 52A, pp. 7-17, 2010.

[2] C. Holston, S. R. Lopez-Permouth, and N. O. Ertas, "Rings Whose Modules Have Maximal Or Minimal Projectivity Domain," Journal of Pure and Applied Algebra 216, pp. 673-678, 2012.

[3] F. W. Anderson and K. R. Fuller, Rings and Categories of Modules (Second Edition), New York, 1992.

[4] I. Kaplansky, "Fields and Rings (Second Edition)," Chicago Lectures in Mathematics Series, pp. 165-168, 1972.

[5] F D Lestari et al 2019 J. Phys.: Conf. Ser. 1211012053

[6] R. Wisbauer, Foundations of Module and Ring Theory, Germany, 1991.

[7] W. A. Adkins and S. H. Weintraub, Algebra An Approach via Module Theory, New York, 1992. 